\title{
“LADY FRIJOLES": LAS CARAVANAS CENTROAMERICANAS Y EL PODER DE LA HÍPERVISIBILIDAD DE LA MIGRACIÓN INDOCUMENTADA
}

\author{
“Lady Frijoles": Central American Caravans \\ in Mexico and the Power of Hipervisible \\ UNDOCUMENTED MigRATION
}

\section{Amelia Frank-Vitale ${ }^{\star}$ Margarita Núñez Chaim**}

Resumen: Desde, al menos, 2011 las personas migrantes centroamericanas y sus aliadas en México han realizado caravanas, en las que combinan el acompańamiento humanitario con las protestas políticas para proteger a las personas en su caminar y exigir el respeto a sus derechos en el territorio mexicano. En 2018 y 2019, este fenómeno tomó una nueva dimensión cuando miles de personas migrantes, en su mayoría hondureñas, se organizaron en caravanas que empezaron en Centroamérica por primera vez. En el presente artículo, como dos antropólogas que hemos acompañado distintas caravanas en la última década, exploramos la naturaleza de éstas como protesta política y social, que desafía los límites de los procesos migratorios. Nos enfocamos en la hípervisibilidad de la migración que reivindica los derechos de las personas migrantes, al ser la caravana no sólo una exigencia por pasar por el territorio

\footnotetext{
* Investigadora en el Departamento de Antropología, Universidad de Michigan. Líneas de investigación: migración, violencia, Honduras. Correo electrónico: ameliafv@umich.edu. ORCiD: 0000-0002-6828-6653.

** Investigadora en el Centro de Investigaciones y Estudios Superiores en Antropología Social (CIESAS), unidad Ciudad de México. Líneas de investigación: migración, violencias, género. Correo electrónico: magui.nunezchaim@gmail.com. ORCiD: 0000-0002-8261-7172.
}

Fecha de recepción: 01/09/2019, fecha de aceptación: 20/11/2019, fecha de publicación: $31 / 01 / 2020$.

(c) $\mathbf{\text { EY-NC-ND }}$ Páginas 37-61 
mexicano, sino una exigencia de hacerlo con dignidad. Estigmatizada como "ingrata" por la prensa mexicana y celebrada cuando se entregó a Estados Unidos, "lady frijol" se convirtió en el símbolo de esta exigencia al rechazar comida donada. En este artículo argumentamos que la caravana de migrantes fusionó este tipo de demandas "sin disculpas" por el derecho a existir, en las que las personas se mueven a través del territorio sin pedir permiso y, al hacerlo, tienen un impacto real en el discurso público y la política. Sin embargo, también reconocemos que los impactos en el corto plazo son limitados e incluso pueden resultar negativos, ya que las personas de la caravana también enfrentan represión y criminalización, pues las deportaciones de personas migrantes centroamericanas continúan a la alza y en las fronteras se refuerza la militarización como respuesta. Aun así, frente a este contexto, las personas, principalmente hondureñas, continúan emigrando en caravanas con un orgullo desafiante.

Palabras clave: Caravanas, migración indocumentada, hípervisibilidad, acción colectiva, resistencia.

Abstract: Since at least 2011, Central American migrants and their allies in Mexico have staged caravans, combining humanitarian accompaniment with protest, protecting individuals from harm while demanding their rights be respected while in Mexican territory. In 2018 and 2019, this phenomenon took a new dimension, as tens of thousands of mostly Honduran migrants organized themselves into caravans, starting from Central America for the first time. As two anthropologists who have been present in many caravans over the last decade, we explore the nature of caravans as protest, while identifying the limitations to that process. We focus on the unapologetic hypervisibility of the caravan and the demand to not only be allowed to pass through Mexican territory but to be treated with dignity. "Lady frijol" became the symbol of this demand, rejecting donated food, bullied as "ungrateful" by Mexican media, and then celebrated when she turned up in the United States. We argue that this kind of in-your-face demand of a right to exist as one wishes and move through space without seeking permission has coalesced in the form of the migrant caravan and, in doing so, had real impact on public discourse and politics. We also recognize, however, that the short-term impacts are 
Amelia Frank-Vitale

Margarita Núñez Chaim
"Lady frijoles": las caravanas centroamericanas y el poder...

limited and even negative, as caravaneros face repression and criminalization, deportation of Central Americans continues unabated, and borders are being further militarized as a response. Still, in the face of this, Hondurans continue to migrate, proudly defiant, in caravans.

Keywords: Caravans, undocumented migration, hypervisibility, collective action, resistance.

\footnotetext{
"En caravana / porque no tenemos lana en caravana / busco el sueño de mañana en caravana / porque a mi me dio la gana ya me voy pero me voy en caravana" Chiky Rasta, En Caravana
}

"En Honduras no comemos frijoles", dijo. O según los medios así fue lo que dijo. Personas a su alrededor lo cuentan un poco diferente pero, con esta frase reporteada, la señora que lo dijo se hizo famosa dentro y fuera de la caravana. Según lo que se cuenta, en algún punto de la caravana, al ser ofrecido una vez más un plato de arroz y frijoles, la mujer hondureña lo rechazó sin pena ni disculpas, casi regañando a quien se lo había ofrecido con la absurda frase de

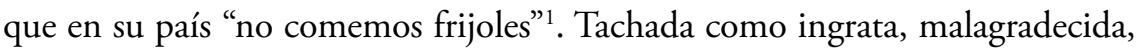
maleducada, etc., aquí la queremos tomar como un símbolo fuerte de lo que era la caravana en sí: una exigencia hacia los poderes del mundo de dejarnos pasar sin pedir disculpas por exigirlo. Como "lady frijoles", la caravana es una forma en la que las personas centroamericanas atraviesan el territorio mexicano sin esconderse, sin buscar pasar desapercibidas. Al contrario, es una forma visible de emigrar que reivindica el derecho a migrar.

Desde, al menos, 2011 las personas migrantes centroamericanas y sus aliadas en México han realizado caravanas, en las que combinan el acompañamiento humanitario con las protestas políticas para proteger a las personas en su caminar y exigir el respeto a sus derechos en el territorio mexicano. En 2018

${ }^{1}$ Es absurdo, porque, en Honduras, como en todo Centroamérica, una de las comidas principales es el frijol. Hay variedad, sí, el color del frijol y la manera de prepararlo es diferente de lo que se encuentra en México, pero el frijol no es una comida extraña para una hondureña. 
y 2019, este fenómeno tomó una nueva dimensión cuando miles de personas migrantes, en su mayoría hondureñas, se organizaron en caravanas que empezaron en Centroamérica por primera vez. En el presente artículo, como dos antropólogas que hemos acompañado distintas caravanas en la última década, exploramos la naturaleza de éstas como protesta política y social, que desafía los límites de los procesos migratorios. Nos enfocamos en la visibilidad de la migración que reivindica los derechos de las personas migrantes, al ser la caravana no sólo una exigencia por pasar por el territorio mexicano, sino una exigencia de hacerlo con dignidad.

Estigmatizada como "ingrata" por la prensa mexicana y celebrada cuando se entregó a Estados Unidos, "lady frijoles" se convirtió en el símbolo de esta exigencia al rechazar comida donada. En este artículo argumentamos que la caravana de migrantes fusionó este tipo de demandas "sin pedir disculpas" por el derecho a existir, en las que las personas se mueven a través del territorio sin pedir permiso y, al hacerlo, tienen un impacto real en el discurso público y la política. Sin embargo, también reconocemos que los impactos en el corto plazo son limitados e incluso pueden resultar negativos, ya que las personas de la caravana también enfrentan represión y criminalización, las deportaciones de personas migrantes centroamericanas continúan a la alza y en las fronteras se refuerza la militarización como respuesta. Aun así, frente a este contexto las personas, principalmente hondureñas, continúan emigrando en caravanas con un orgullo desafiante.

En lo que sigue, empezamos con la narración de un momento clave de la caravana/éxodo de octubre de 2018. En esta historia, vemos claramente la organización incipiente de la caravana, el reto que presenta dicha organización ante las autoridades mexicanas y el orden esperado entre quienes mandan y quienes acceden a lo que dice la "ley." De ahí ofrecemos un análisis sobre la manera en que la hípervisibilidad se constituye como una forma de resistencia. Para concluir, volvemos a la caravana, ahora en la frontera norte de México, para reflexionar sobre los límites de la acción colectiva migrante ante el régimen hegemónico de fronteras cerradas.

La información que se presenta proviene del trabajo de campo de doctorado realizado por ambas antropólogas. Mientras que Margarita Núñez acompañó el éxodo de octubre de 2018 a diciembre del mismo ańo, desde Ciudad de Guatemala hasta Tijuana, Amelia Frank-Vitale acompañó el trayecto en 
el sur de México, por Chiapas y Oaxaca, y en el norte, en Tijuana. Ambas también han realizado trabajo de campo acompañando otras caravanas en años anteriores $^{2} y$, posteriormente, en $2019^{3}$.

Nuestras metodologías son similares: por lo general consisten en hacer observación participante, acompañar y realizar entrevistas semi- o noestructuradas, a veces grabadas en voz y a veces no, según las circunstancias y las preferencias de la persona entrevistada. Para ambas, la observación participante durante las caravanas consistió en "caminar" con ellas y, por lo tanto, en realizar una "etnografía en movimiento", más allá de una etnografía multisituada, como muchas veces se usa en los estudios migratorios. El texto que aquí se presenta es una aproximación etnográfica que nutre algunas de las reflexiones teóricas que ambas tuvimos en el proceso de acompańamiento durante los últimos meses de 2018 y que conforman parte de nuestra investigación doctoral.

\section{"Lo que queremos nosotros es pasar": la organización de la caravana en el tránsito}

"Necesitamos una comisión del éxodo para que puedan dialogar directamente con el comandante de la Gendarmería a cargo del operativo", dijo Arturo

\footnotetext{
${ }^{2}$ Amelia fue parte de la primera caravana de migrantes que se realizó en México, en enero del año 2011, y varias otras caravanas de migrantes en 2012, 2013, y 2014. Ella vio cómo iban evolucionando, de grupos de trescientas personas recorriendo un tramo corto en el sur de México en 2011, a las más de mil personas que llegaron a la Ciudad de México y se manifestaron frente de Los Pinos en 2014 (Frank-Vitale, 2011). Amelia estaba realizando trabajo de campo en Honduras, enfocada en la vida después de la deportación en San Pedro Sula (Frank-Vitale, 2019), cuando se dio la caravana de octubre de 2018, que tiene sus antecedentes en las otras caravanas en las cuales se había participado, pero que tuvo otra forma - al iniciar en Centroamérica - y una magnitud distinta.

${ }^{3}$ Tras la caravana que salió el 12 de octubre de 2018 de San Pedro Sula y empezó el recorrido por México el 20 de octubre (la cual narramos y retomamos aquí), es realmente difícil numerar las caravanas que siguieron y contabilizar a las personas que se unieron en esta modalidad de migración. Las convocatorias para "salir en caravana" empezaron a ser continuas y constantes durante los siguientes meses. En un inicio se llamó a ésta la "primera caravana”, y se contabilizaron dos más, "la segunda" y "la tercera", que se conformaron por contingentes menores (aproximadamente entre dos y cuatro mil personas) y que comenzaron el recorrido por México en las siguientes dos semanas de octubre. Sin embargo, la migración en grupo empezó a ser un flujo constante en los últimos meses de 2018 y los primeros de 2019, lo que volvió obsoleto contabilizar "caravanas". El 15 de enero de 2019 volvió a haber una convocatoria numerosa, de aproximadamente cuatro mil personas. Margarita Núñez acompañó ese grupo desde San Pedro Sula hasta que llegó a la Ciudad de México en febrero de 2019, como parte también, de su trabajo de campo doctoral.
} 
Peimbert, Ombudsman de Oaxaca. Atrás de él había una barrera de 300 policías federales con equipos antimotines, seguida de otra barrera de agentes del Instituto Nacional de Migración (INM), más “perreras” ${ }^{4}$ y autobuses en los que, desde que el éxodo pisó suelo mexicano, subían a las personas para deportarlas a sus países, así que nadie se fiaba de esos autobuses. Eran pasadas las 4 de la mañana del sábado 27 de octubre de 2018, ese día el éxodo lograba una primer meta en su tránsito por México: dejaba el estado de Chiapas y alcanzaba Oaxaca. El trayecto por recorrer, acordado en la asamblea del día anterior, partía de Arriaga, Chiapas, hacia Tapanatepec, Oaxaca. En ese momento nos encontrábamos en el inicio del puente Arenas, a casi 11 km de Arriaga, era de madrugada, no había absolutamente nada de luz, nada alrededor, los celulares no tenían señal (probablemente porque el operativo de la Gendarmería incluía bloqueadores de señal). Las personas, más de siete mil ${ }^{5}$, venían caminando pocos kilometros antes de llegar al bloqueo que se instaló después de una curva muy pronunciada en la carretera, de manera que era imposible saber que había un despliegue policiaco de esa magnitud hasta que lo tenías a unos cuantos metros, era una emboscada. "Me recuerda a Nochixtlán y no quiero otro Nochixtlán," remató el Ombudsman de Oaxaca ${ }^{6}$.

Un día antes, el éxodo se había trasladado de Pijijiapan a Arriaga. Como empezó a ser ya rutina: salíamos de madrugada y caminábamos hasta que el cuerpo aguantara, hasta que encontráramos un aventón, o hasta que los rayos del sol fueran agotadores y necesitáramos parar, así, poco a poco, en el transcurso del medio día y hasta la tarde, íbamos llegando al siguiente punto. Al llegar había que buscarse un espacio por el parque central y las calles aledañas. Las personas improvisaban carpas con plásticos, cartones, cuerdas

\footnotetext{
${ }^{4}$ Las camionetas del Instituto Nacional de Migración que se utilizan para trasladar a las personas migrantes detenidas hacia las estaciones migratorias son conocidas como perreras puesto que son vans tradicionales cuyas ventanas están protegidas con barrotes.

${ }^{5}$ De acuerdo al conteo realizado por el Ayuntamiento de Suchiate el 20 de octubre de 2018, cuando las personas habían cruzado la frontera de México con Guatemala y pernoctaron en Ciudad Hidalgo, el grupo de personas se conformaba por: 2,622 hombres, 2,234 mujeres, 1,070 niños y 1,307 niñas. En total estamos hablando de un mínimo de 7,233 personas al entrar en México. Mientras algunas personas tomaron otro camino y se apartaron de la caravana en algún momento de la trayectoria, muchos otros se sumaron en distintos puntos también, haciendo un conteo preciso de "la" caravana imposible.

${ }^{6}$ Con "Nochixtlán” el Ombudsman hizo referencia a una escena parecida de 2016 cuando los policías federales buscaron desalojar a manifestantes de las carreteras de Oaxaca; lo cual resultó en seis personas muertas y más de 100 personas heridas.
} 
Amelia Frank-Vitale Margarita Núñez Chaim
"Lady frijoles": las caravanas centroamericanas y el poder...

y cualquier cosa que se tuviera a la mano para resguardarse del sol. Llegaban personas del municipio, voluntarias, familias que querían apoyar y llevaban alimento, agua, medicinas. Poco a poco, cada quién se iba instalando para comer, lavar ropa, buscar donde bañarse, descansar y recuperar la energía para la caminata que vendría al día siguiente.

En el kiosco del parque central de Arriaga, como también ya era costumbre, se instaló un micrófono con un amplificador en el que autoridades municipales daban avisos, personas solidarias ofrecían las donaciones que llevaban, migrantes se acercaban para vocear a sus familiares que se habían separado en el camino, algún voluntario anunciaba cosas perdidas, alguien más amenizaba de repente con música, etc. Sin embargo, en esta ocasión en Arriaga, de repente en el audio se escuchó "presidencia de la República," y siguió una voz un tanto conocida, era Enrique Peña Nieto, entonces presidente de México, con el siguiente mensaje:

Hoy quiero dirigir un mensaje a cada uno de los migrantes centroamericanos que están en México. Quiero decirte, en primer lugar, que los mexicanos somos hospitalarios y especialmente solidarios con quienes pasan por momento difíciles. Somos un país que valora y reconoce la dignidad de las personas migrantes. Casi todos nosotros tenemos algún pariente o amigo cercano que ha migrado. Sabemos muy bien que lo que buscas es una oportunidad, que quieres construir un nuevo hogar y un mejor futuro para tu familia y seres queridos. Hoy, México te extiende la mano. Queremos que tú y todos los migrantes se sientan tranquilos y protegidos. Para apoyarte, el gobierno de México está lanzando, el día de hoy, el plan Estás en tu casa. Estando en México, podrás recibir atención médica, e incluso mandar a tus hijos a la escuela. También tendrás una identificación oficial temporal para hacer los trámites que necesites mientras regularizas tu situación migratoria. Además, ese documento te permitirá entrar y salir de los albergues de Chiapas o Oaxaca cuando quieras. Y algo muy importante, al incorporarte al Plan, podrás acceder al Programa de Empleo Temporal. Para aprovechar todos estos beneficios son indispensables dos requisitos: uno, que te encuentres en los estados de Chiapas o Oaxaca, y dos, que tú y los familiares que te acompañan ya hayan solicitado su ingreso o refugio con el Instituto Nacional de Migración. Si aún no lo han hecho y forman parte de la Caravana Migrante 
Amelia Frank-Vitale

Margarita Núñez Chaim
"Lady frijoles": las caravanas centroamericanas y el poder...

o arribaron previamente a México todavía están a tiempo para acercarse al Instituto Nacional de Migración para iniciar los trámites que permitan regularizar su situación. Este Plan solamente es para quienes cumplen con las leyes mexicanas y es un primer paso hacia una solución permanente para aquellos que obtengan la condición de refugiado en México. Los mexicanos que viven en Chiapas y Oaxaca también se beneficiarán de esta decisión, ya que se amplía el Programa de Empleo Temporal para los residentes de estos dos estados. Estimados migrantes: México los quiere proteger y apoyar, la única manera en que podremos hacerlo es si ustedes regularizan su estancia en el país y cumplen con nuestras leyes. Los invito a que se acerquen a la brevedad al personal migratorio que está listo para ayudarles. México es un país que ofrece oportunidades a quienes vivimos aquí. Recibir a quienes vienen de fuera nos enriquece. Muchas gracias. (Presidencia Enrique Peña Nieto, 2018).

El mensaje estuvo sonando en repetidas ocasiones, las personas lo escuchaban y dudaban, a veces sonaba como una buena propuesta: trabajo, acceso a la salud, a la educación. Pero luego venían las condiciones: quedarse en Chiapas o Oaxaca, en "albergues". Para entonces, todas y todos también desconfiaban cuando escuchaban las palabras "albergue" e "Instituto Nacional de Migración", pues en los primeros días, cuando el éxodo cruzó el puente internacional Rodolfo Robles, fue recibido por la Policía Federal con gases lacrimógenos y se cerraron las puertas de México, entonces, los agentes del INM se acercaron con la promesa de "dejarles pasar, llevarles a un albergue y darles papeles." La sorpresa fue que las primeras personas en pasar y subirse a los autobuses fueron directo de regreso a Honduras, las que les siguieron fueron a las instalaciones de la Feria Mesoamericana en Tapachula, que había sido habilitada como extensión de la Estación Migratoria Siglo XXI. Es decir, el "albergue" había resultado en una cárcel, un centro de detención de migrantes, y la promesa de papeles resultó en órdenes de deportación.

Así que una vez que se escuchó la oferta del presidente de México, la gran mayoría del éxodo ya no creía lo que oía. Para quienes vienen de Centroamérica tampoco es algo nuevo aquello de desconfiar de las autoridades, de escuchar promesas incumplidas, de escuchar programas de gobierno que resultan en engańos. Los gobiernos de Honduras, El Salvador y Guatemala también tienen una larga historia en este sentido, los escándalos de corrupción y desvío 
Amelia Frank-Vitale Margarita Núñez Chaim
"Lady frijoles": las caravanas centroamericanas y el poder...

de fondos en las últimas décadas han dejado a la mayoría de las poblaciones en estos países sin servicios básicos como la salud. Precisamente esto también es parte de las razones por las que las personas dejan sus países.

La oferta que planteaba el gobierno federal no era nueva, se estaba ofreciendo lo que la legislación migratoria mexicana ya contemplaba: la posibilidad de solicitar la condición de refugiado 7 , mientras se solicita, obtener una Tarjeta de Visitante por Razones Humanitarias (TRH), mejor conocida como visa humanitaria $^{8}$. Sin embargo, con una restricción que nadie veía favorable: sólo poder permanecer en Chiapas o Oaxaca, en un “albergue." Además, también hay que sumar que muchas personas migrantes ya habían pasado por procesos de regularización en México en migraciones anteriores, o tenían conocidos que habían pasado por esos procesos, y sabían que, en la mayoría de los casos, las solicitudes de refugio son rechazadas. También sabían que los trámites duran meses, cuando no años, y no cuentan con los recursos para mantenerse durante dichos procesos administrativos. Sabían de los bajos salarios que se ofrecen a las personas centroamericanas y de las difíciles condiciones de vida en Chiapas o Oaxaca para quienes hablan como catrachos.

De cualquier forma, el plan Estás en tu casa no resolvía las necesidades de las personas, ni tenía las condiciones para que la oferta tuviera credibilidad. Como sucede con las políticas sociales en general, y las migratorias en particular, estaba planteada para que las personas hicieran lo que el gobierno quería: que dejaran de avanzar. No podía caber más ingenuidad en su planteamiento, las personas habían dejado todo por buscar una oportunidad de vida que les ha sido negada en sus países, no iban a aceptar ninguna propuesta que no cumpliera con ese objetivo, y ellas sabían que en México, pidiendo refugio y quedándose en un "albergue" en Oaxaca o Chiapas, no lo iban a lograr. Así, en la asamblea de la tarde del viernes 26 de octubre en la plaza central de Arriaga,

\footnotetext{
${ }^{7}$ En México, según la Ley sobre Refugiados, Protección Complementaria y Asilo Político, la solicitud de condición de refugiado puede reconocerse debido a fundados temores de ser perseguido por motivos de raza, religión, nacionalidad, género, pertenencia a determinado grupo social u opiniones políticas, se encuentre fuera del país de su nacionalidad y no pueda o, a causa de dichos temores, no quiera acogerse a la protección de tal país; o que, careciendo de nacionalidad y hallándose, a consecuencia de tales acontecimientos, fuera del país donde antes tuviera residencia habitual, no pueda o, a causa de dichos temores, no quiera regresar a él.

${ }^{8}$ La Tarjeta de Visitante por Razones Humanitarias es un documento que expide el Instituto Nacional de Migración y que permite una estancia legal temporal en México cuando la persona que la solicita ha sido víctima de algún delito, o cuando se encuentra en el proceso de solicitud de la condición de refugiado ante la Comisión Mexicana de Ayuda a Refugiados.
} 
Amelia Frank-Vitale

Margarita Núñez Chaim
"Lady frijoles": las caravanas centroamericanas y el poder...

Chiapas, las personas tomaron una decisión fundamental: no aceptar el plan y avanzar, por ahora, con el objetivo de llegar a la Ciudad de México para después decidir qué ruta tomar hacia la frontera con Estados Unidos.

Al día siguiente en la madrugada, el comandante de la Gendarmería a cargo del operativo que bloqueaba el paso del éxodo hacia Oaxaca explicó que la "intención" de su retén era presentar el programa Estás en tu casa. Sí, en la madrugada, sobre un puente en la carretera en medio de la nada, sin luz, sin señal de celular, 300 elementos de la Policía Federal bloquearon el paso para decirles a las más de 7 mil personas caminando que "estaban en casa" y "México les daba la bienvenida". Los agentes del INM presentes decían que les subirían a los autobuses para llevarles a los albergues, registrarles e iniciar sus procesos de regularización. Las sospechas de que el programa fuera un engaño se hacían más fuertes. Lo que se había escuchado antes y había terminado en deportaciones y encierros se repetía: Policía Federal bloqueando el paso (igual que en el puente internacional) y el INM prometiendo "albergue y papeles." Nadie se tomaba ya en serio la propuesta, nadie estaba dispuesto a aceptar. Pero la Gendarmería tenía instrucciones de "no dejar pasar".

La Defensoría de los Derechos Humanos del Pueblo de Oaxaca, la Comisión Estatal de Derechos Humanos de Chiapas (CEDH-Chiapas) y la Comisión Nacional de Derechos Humanos (CNDH) estaban presentes en ese momento porque, al ser ese recorrido el primer tránsito entre estados, habían acordado un acompańamiento coordinado como un "cambio de estafeta". Las comisiones habían empezado el recorrido de avanzada y toparon con el retén. El Ombudsman de Oaxaca, al ver el operativo, se acercó al personal a cargo para establecer un diálogo. Fue así como decidieron que, quienes estaban al frente del operativo debían dialogar de manera directa con las personas del éxodo para llegar a un acuerdo y, dicho diálogo sería mediado por los organismos de derechos humanos.

Así que a través de un megáfono y al frente de la línea en la que el contingente del éxodo se comenzó a agrupar para que, una vez todas y todos juntos, avanzaran hasta el bloqueo policiaco, se convocó a voluntarias y voluntarios que quisieran participar en la "comisión de diálogo" para negociar con el comandante del Gendarmería y los representantes del INM. Se pidieron dos hombres y dos mujeres y las manos empezaron a levantarse, sin mucho más trámite, se formó la comisión. 
Amelia Frank-Vitale

Margarita Núñez Chaim
"Lady frijoles": las caravanas centroamericanas y el poder...

El éxodo esperó hasta que la mayor parte del contingente estuviera agrupada para acercarse al bloqueo y presentar la comisión de diálogo. El escenario que planteaba el gobierno parecía que esperaba una confrontación, sin embargo, en la caravana, nadie quería una, "vienen tantas niñas y niños, por ellos, tenemos que ver por ellos”, era la respuesta siempre que las cosas se tensaban y, en esta ocasión, no era la excepción. Así que se decidió que se agruparían para avanzar juntos, fuertes, pero al llegar al frente de la policía, todas y todos se sentarían para evitar cualquier incidente. Esto tomó un par de horas en las que la gente se empezó a estancar en la carretera y el grupo empezó a ocupar uno, dos, tres kilómetros repletos de personas y más, hasta que la vista no alcanzaba para ver el final de la fila. Lo cual también dio tiempo a que la noche empezara a ceder y hubiera un poquito de visibilidad. El contingente de miles avanzó y al llegar a unos metros de la policía, se sentó. Claramente no era lo que la policía esperaba, ellos iban listos para reprimir con cualquier pretexto. La comisión de diálogo estaba lista y sabía lo que el éxodo quería: avanzar.

Finalmente, poco antes del pleno amanecer, la comisión de diálogo se acercó al cerco. Se formó un círculo en el que estaban las y los integrantes de la comisión con el comandante de la Gendarmería, el delegado del INM en Chiapas, el Quinto Visitador de la CNDH, el Ombudsman de Oaxaca y el de Chiapas, así como otros integrantes de estas instituciones, acompañantes del éxodo, personas de organizaciones sociales y, por supuesto, todos rodeados de un sin fin de cámaras, micrófonos y grabadoras de la prensa.

El diálogo comenzó con el comandante: "nuestro interés es darles a conocer el programa de la manera más extensa posible para quitarles las preocupaciones que tengan del mismo [...] Para quienes quieran adherirse al programa, el personal del INM ya está aquí listo para poderlos llevar a un lugar donde puedan iniciar el trámite". Para el éxodo ya no había "preocupaciones" sobre el programa, quedaba clara la intención y hacia dónde iba el operativo, la respuesta comenzó por parte de un chico hondureño que no pasaba los 25 años: "lo que queremos nosotros es pasar", concreto y claro. La palabra fue tomada por otra representante del éxodo, luego por el INM, finalmente personas solidarias y de las comisiones derechos humanos. El comandante concluyó con que tenía que "verificar con sus superiores". El círculo se disolvió y empezó la espera. Al cabo de una media hora regresó el comandante, se 
reagrupó el círculo y la respuesta fue: "está bien, les dejaremos pasar, pero en cada punto que avancen les iremos informando del programa".

El sol ya empezaba a quemar cuando el operativo se retiró y el éxodo retomó su paso y su ritmo. "Nos hicieron esperar para hacernos caminar bajo el sol”, decían muchas personas. No estaban equivocadas, si la confrontación directa y la intimidación con antimotines no pudo frenar el éxodo, la táctica, tampoco nueva, comenzó a ser apostarle al desgaste de las personas. Pero de nuevo, esta táctica también resultaba ingenua ante la voluntad de quienes caminaban.

Desde un inicio, en Honduras, el éxodo empezó a generar sus mecanismos de organización: grupos de WhatsApp y Facebook por departamentos para avanzar de manera conjunta ${ }^{9}$. Sin embargo, a los pocos días, durante el tránsito por Guatemala, esta organización incipiente fue rebasada por completo por la magnitud que tomó la salida de personas de Honduras, El Salvador y Guatemala. Una vez que las personas llegaron a Tecún Umán, donde se agruparon antes de cruzar la frontera con México, comenzaron las

\footnotetext{
${ }^{9}$ La organización inicial del éxodo desde Honduras se dio a partir de algunas convocatorias realizadas en redes sociales para "emigrar juntos", que después se viralizaron a partir de los medios de comunicación locales en Honduras, principalmente, la cadena de televisión $H C H$, que comenzó a transmitir en vivo el grupo inicial, de no más de 200 personas, que se había reunido en la Terminal Metropolitana de San Pedro Sula. Cuando las personas se comenzaron a sumar a la caravana, en Honduras, empezaron a organizarse entre familias, colonias, barrios y departamentos, y para ello, realizaron grupos de WhatsApp y Facebook para coordinarse. Todo esto surgió de una manera bastante espontánea pues la mayoría de las personas decidieron unirse en cuestión de horas o días al enterarse de ese grupo reunido en la Terminal. Sin embargo, en un par de días el grupo pasó de 200 a cuatro mil personas, que se estimaron cruzaron la frontera de Honduras con Guatemala entre el 13 y 15 de octubre. Para entonces, la organización por redes sociales se desbordó y dejó de ser funcional. Cuando las personas llegaron a la frontera con México, se estimaban arriba de siete mil, por lo que la única forma de organización más o menos estable empezaron a ser las reuniones nocturnas o asambleas donde se decidía lo básico: a dónde se seguiría el día siguiente. Sin embargo, nunca hubo una toma de decisiones centralizada ni con la capacidad de generar un consenso amplio. De hecho, en varias ocasiones las decisiones tomadas en la asamblea se cambiaban de un momento a otro, por circunstancias emergentes. $\mathrm{Al}$ final, siempre prevalecía la voluntad y toma de decisiones individualizada, pues a pesar de haber salido en grupo y con la decisión de ir en colectivo, las personas tomaron la decisión de salir de sus casas de manera autónoma e individual, lo que siempre terminaba por impedir que "alguien más" decidiera por ellas mismas. Esto mismo generaba que no hubiera nadie con la legitimidad para ser "líder" u "organizador", las personas que por momentos tomaban papeles activos y liderazgos eran siempre rotativas y cambiantes. Adicionalmente, esto generaba que quienes acompañábamos, antropólogas entre otras organizaciones y activistas, tampoco pudiéramos injerir en la toma de decisiones, simplemente, apoyábamos en temas logísticos y emergentes.
} 
Amelia Frank-Vitale

Margarita Núñez Chaim
"Lady frijoles": las caravanas centroamericanas y el poder...

asambleas vespertinas que funcionaban para coordinar el camino: cuándo se sale al siguiente punto, cuál es ese siguiente punto, a qué hora, y algunos avisos misceláneos.

El retén de la Policía planteó un reto organizativo para el éxodo: la necesidad de representantes que intervinieran en las situaciones de emergencia in situ, que tuvieran legitimidad en el grupo y, suficientes como para, por lo menos, tener algo de capacidad de acción con el grupo. La asamblea del día anterior, en la que se habían tomado las decisiones respecto a la propuesta del gobierno federal, facilitó el hecho de que, quienes se postularon como comisión de diálogo, sabían la postura de una gran parte del éxodo y, al momento del bloqueo, pudieron actuar.

\section{La hípervisibilidad de la vulnerabilidad como forma de resistencia}

La magnitud del éxodo, un pueblo andante, hizo siempre imposible una coordinación centralizada. Las decisiones básicas se tomaban en las asambleas, lo demás conforme se fuera presentando. Al final, era una organización autónoma y anárquica, la voluntad de cada persona prevalecía, lo que hacía a los liderazgos que surgían en cada circunstancia, frágiles y cambiantes. "¿Y vos quién sos para decirme qué hacer?”, siempre respondía alguien cuando otra persona asumía que podía tomar una decisión por las y los otros. Era cierto, esas más de siete mil personas habían decidido salir de sus casas por su propia voluntad, de manera individual. No obstante, todas tenían dos objetivos claros: ir a Estados Unidos y avanzar juntas. El segundo objetivo era el que permitiría alcanzar el primero, de eso nadie tenía ninguna duda, y por eso, todas permanecían juntas por su propia voluntad, acuerpándose en el colectivo y en su hípervisibilidad.

La autonomía y la anarquía de la organización no sólo respondía a la magnitud y las circunstancias cambiantes, también respondía a otro factor fundamental: la desconfianza en las autoridades y actores externos al éxodo. Quienes huyen de Centroamérica han aprendido, casi siempre a la mala, por historias de vida marcadas por exclusiones y desigualdades, que no pueden confiar en nadie más que en ellas y ellos mismos, que no pueden depender de nadie más que de sí mismas. 
Amelia Frank-Vitale

Margarita Núñez Chaim
"Lady frijoles": las caravanas centroamericanas y el poder...

Esta organización-desorganizada, desde las necesidades concretas y cotidianas, resultó muy efectiva en tanto que resolvía de manera práctica las circunstancias que se presentaban. La organización permitía avanzar de manera operativa, funcionaba para resolver en terreno. Pedirle más al éxodo en términos organizativos era no comprender su naturaleza. Las reivindicaciones se hicieron en la manera de migrar en sí misma, en el caminar de forma hípervisible, no en las asambleas, ni los comités. La hípervisibilidad expuso la vulnerabilidad de las personas de Centroamérica ante el mundo, sus condiciones de precariedad, y al mismo tiempo, esta vulnerabilidad mostró su capacidad de su resistencia a los poderes del mundo ${ }^{10}$.

En la literatura que trata sobre la condición de poblaciones migrantes o refugiadas, los temas de visibilidad e invisibilidad han formado una base importante de la contribución teórica sobre la condición humana de poblaciones migrantes. Se ha identificado el uso estratégico de la visibilidad e invisibilidad (Córdoba González de Chávez, 2018) en términos de cómo las personas se manifiestan y reclaman su derecho a existir dentro del espacio (estado nación) donde viven. Una política de (in)visibilidad se ve en la comunidad de migrantes/refugiados en Malasia (Vries, 2016), o en los que están en el proceso de asilo en Alemania (Bhimji, 2016). La visibilidad, entonces, se entiende como un logro, para que la población migrante/refugiada sea reconocida en sí misma y puede participar en los procesos que le afectan dentro del país donde busca seguir viviendo o quedarse.

Sin embargo, la hipervisibilidad se percibe como un componente de la condición de invisibilidad cuando la gente marginada se queda sin ser vista o, por su misma condición, se convierte en híper vista pero por desviarse de la norma; así, pasan de ser personas ignoradas a personas estigmatizadas. La hípervisibilidad se ha utilizado de esta manera para hacer referencia a personas que están expuestas ante el poder, como el caso de los musulmanes en Estados Unidos en el período de intensa islamofobia después del 11 de septiembre (Shams, 2018), los cuerpos de las mujeres negras en espacios de ocio (Mowatt, French, and Malebranche, 2013) o, por lo general, la condición de la mujer en el oeste siempre sujeta a la mirada masculina (Hammer, 2016). La hípervisibilidad, entonces, generalmente se refiere a una condición impuesta hacia la gente marginada/excluida cuando su condición de diferencia relativa

\footnotetext{
${ }^{10}$ Para una crítica del humanitarianismo, revisar Ruiz-Giménez Arrieta (2017).
} 
Amelia Frank-Vitale

Margarita Núñez Chaim
"Lady frijoles": las caravanas centroamericanas y el poder...

a la norma resulta visible ante el poder, visible precisamente por ser desviante. En esta literatura, la condición de hípervisibilidad pasa de ser visible en el sentido de incluido y contado, a ser hípervisto y, aún, excluido. Esta exclusión se vive de otra manera que una exclusión basada en invisibilidad, pero siempre la hípervisibilidad es, en el fondo, una condición de otredad.

Para nosotras, estas dos contribuciones de la visibilidad e hípervisibilidad se suman a la función de resistencia. En el contexto de la caravana identificamos un uso estratégico de la hípervisibilidad en su acepción de agencia, como los casos de la visibilidad de las poblaciones migrantes y, a la vez, utilizando precisamente su condición colectiva de ser otros buscando pasar por estos espacios sin quedarse. Aquí vemos el uso estratégico de la hípervisibilidad del colectivo como una manera de protegerse y reclamar su dignidad, sin pedir disculpas por hacerlo o por ser quienes son y retar una hípervisibilidad impuesta y excluyente. La hípervisibilidad de la caravana fue práctica - así podían acceder a una seguridad usualmente posible a través de una híperinvisbilidad. A la vez la hípervisibilidad de la caravana fue en sus términos, no impuesta, haciendo hípervisible precisamente su condición del otro, su necesidad, y su vulnerabilidad ante un sistema que los expulsa.

La migración visible fue una forma en la que las y los migrantes expusieron (en el sentido de mostrar) su vulnerabilidad, al tiempo que se expusieron (en el sentido de ponerse en riesgo, como se mostró en el retén de la Policía) ante la vulnerabilidad, ésta última entendida como un efecto social del poder, producida políticamente y distribuida de manera desigual. De esta forma, la migración visible consistió en un acto en el que la vulnerabilidad se expuso (en ambos sentidos, mostrarse y ponerse en riesgo), como una forma de resistencia en sí misma; desafiando así la lógica humanitaria (machista, racista y colonial) en la que las personas migrantes, al ser percibidas como "vulnerables" son excluidas de su capacidad de agencia y, a su alrededor, se activan políticas paternalistas cuyo objetivo es regular y controlar (Butler, Gambetti y Sabsay, 2016). En este sentido, la caravana de 2018 desafió la lógica del humanitarismo del gobierno (McFalls, 2010), organizaciones de derechos humanos, iglesias y hasta medios de comunicación que, en México, estaban acostumbrados a trabajar con migrantes que llegaban de uno en uno a sus ventanillas, de manera invisible, que merecen ser atendidos mientras quedan en la posición de víctimas necesitadas (Ticktin, 2006). 
La hípervisibilidad, como una forma de emigrar propia de las y los caravaneros, consistió en una exposición corporal deliberada al poder: las personas sabían los riesgos que estaban tomando, eran conscientes de la posibilidad de ser detenidas, deportadas, violentadas, e incluso de la posibilidad de morir, y hubo quienes murieron. No obstante, esta exposición deliberada debe entenderse como una resistencia al mismo poder, a través de la acción de emigrar. Al mostrar el cuerpo colectivo como el único vehículo para lograr su objetivo, las y los caravaneros hicieron visible su vulnerabilidad. De forma que su resistencia radicó, precisamente, en la visibilidad de esta condición de vulnerabilidad (Butler, 2016). Así la hípervisibilidad de su migración consistió en un movimiento de resistencia por el derecho a existir sin pedir disculpas.

Lady frijoles encarnó esta resistencia al ser estigmatizada y rechazada. Dentro de la lógica racista, machista y colonial del humanitarismo, quienes son vulnerables carecen de poder. Lady frijoles desafío esta lógica al rechazar "ayuda" y ser "malagradecida". Precisamente porque ella, como la caravana, no demandaba "ayuda," demandaba un trato digno, comida y no sobras. La acción de rechazar un plato de comida develó que la lógica humanitaria no reconoce a las personas como tales, como sujetos políticos capaces de acción y resistencia: capaces de hartarse y cansarse de las circunstancias, de enojarse y demandar un trato digno. Pues la lógica humanitaria ve a las personas "vulnerables" con lástima, con condescendencia, es vertical y refuerza la exclusión. De ahí que cuando una mujer, pobre, migrante y racializada, se harta y dice que no, es violentada a través de la ridiculización: "lady frijoles".

La caravana, como lady frijoles, fue un acto de resistencia en sí misma, a través de exponer su vulnerabilidad: de hacerse hípervisible en la acción colectiva de caminar. Así, la vulnerabilidad, fuera de la lógica humanitaria, contiene un efecto movilizador. La vulnerabilidad es resistencia. Lo cual tampoco implica que dicha vulnerabilidad se "supera", - esto implica caer en la misma lógica en la que se excluye la agencia de la vulnerabilidad-. Más bien, la vulnerabilidad contiene la potencia de la agencia (Butler, 2016). La caravana, a través de su hípervisibilidad, reivindicó su derecho a existir. La migración visible fue una resistencia al sistema de poder que busca negar el derecho a una vida digna a aquellas personas racializadas, generizadas y empobrecidas, a pesar de que dichas personas no "superan" su condición de vulnerabilidad, políticamente construida. 
De esta forma, el éxodo desafió de manera muy práctica esta lógica racista, machista y colonial. Al salir de la clandestinidad, decidir emigrar de manera colectiva y visible, caminando por carreteras federales y durmiendo en las plazas centrales de cada pueblo en la ruta migratoria, el éxodo adquirió una hípervisibilidad que le permitió avanzar de una forma en la que cada paso en sí mismo era una reivindicación por un trato digno, reconocimiento y el derecho de todas las personas, sin distinción alguna, a buscar una oportunidad de vida. Pensar que estas reivindicaciones tendrían que articularse a través de la organización -que como se desarrolló fue un carácter operativo- también forma parte de lógica humanitaria que excluye la agencia de la vulnerabilidad.

La resistencia que representó esta hípervisibilidad de la vulnerabilidad tuvo un impacto real en el discurso público y la política. Los efectos de mediano y largo plazo aún no son claros y están por verse. Sin embargo, en el corto plazo, Estados Unidos y México han recurrido a la lógica racista, machista y colonial que refuerza la idea de vulnerabilidad como pasiva en su beneficio. Colocándose como países bajo "amenaza" y, de tal forma, "vulnerables" a las personas migrantes, reforzando así su exclusión con un discurso de miedo y de odio que se concretiza en políticas y acciones de contención de la migración. En sí, los súperpoderes de la región han contestado a la migración organizada e hípervisible con las fuerzas armadas, como si fuera una invasión armada en vez de un éxodo de gente buscando (sobre)vivir.

\section{Llegando al límite: Enfrentando las fronteras de la acción colectiva}

“¿En qué número vamos hoy?” Después de un mes en Tijuana, esto se ha convertido en una pregunta común entre las y los caravaneros. La energía efervescente que impulsaba a la gente hacia adelante desde el sur de México se ha disipado, y las personas se han asentado en una rutina de dejar transcurrir los días, de esperar su turno. El sistema de la "lista de espera" en los puertos de entrada es una invención de los mismos solicitantes de asilo ${ }^{11}$, una forma de encontrar sentido en el caos impuesto por los guardias fronterizos que, durante algunos años, han estado decidiendo arbitrariamente cada día a cuántas personas se les permite el ingreso para solicitar asilo. Las y los solicitantes de

${ }^{11}$ El asilo en Estados Unidos es un proceso al que puede acceder cualquier persona que tema por su vida, que sufra persecución y que sea fundamentada. La persecución debe ser por motivos de raza, nacionalidad, religión, política, o por ser integrante de un grupo social especifico. 
Amelia Frank-Vitale

Margarita Núñez Chaim
"Lady frijoles": las caravanas centroamericanas y el poder...

asilo desarrollaron la lista, asignando números a los que quieren entregarse, y cada día se llama a aproximadamente 80 personas.

Este proceso de espera, lento e individual, no era lo que la mayoría de la gente tenía en mente al atravesar México. Pero la frontera más vigilada del mundo y las políticas migratorias y de asilo de Estados Unidos, han obligado a la acción colectiva a tomar decisiones individuales.

Cuando la caravana llegó por primera vez a Tijuana, la gente comenzó a preguntar: ¿qué hacemos ahora? Algunas personas tenían esperanzas, fe, de que su presencia fuera presión suficiente para que Estados Unidos aceptara dejarles cruzar la frontera, como lo hizo México. Se planearon algunas protestas. Unos cientos de integrantes de la caravana caminaron, con letreros en alto, desde el campamento improvisado en el Deportivo Benito Juárez, hasta el punto de entrada peatonal conocido como El Chaparral. La presencia policial era fuerte, exagerada para la pequeña multitud. Llegaron a El Chaparral y nadie sabía realmente qué hacer. Hablaron con la prensa, sostuvieron carteles y, finalmente, caminaron de regreso al campamento. Algunas personas pensaron: el problema es que la marcha no fue lo suficientemente grande.

Entonces se reorganizaron y se propuso una segunda marcha, más grande. Sin embargo, esta vez, la policía no permitió que los manifestantes cruzaran el puente que los conecta con El Chaparral. Una vez más, un bloqueo de la Policía Federal impidió el avance de las y los caravaneros. Intentaron negociar como lo habían hecho antes en Chiapas: tomaron el altavoz y suplicaron a la policía, rezaron, expresaron reiteradamente su gratitud al pueblo mexicano. La policía, sin embargo, no se movió. Eventualmente, algunos grupos se empezaron a separar y buscaron un camino para rodear el puente. Corrieron por el canal, saltaron sobre muros y cercas, y aun así, al final, se enfrentaron a los cordones de acero del muro fronterizo. También se encontraron con gases lacrimógenos y balas de goma.

Los acontecimientos de este día evidenciaron de manera violenta la realidad que el éxodo enfrentó al llegar a la frontera norte de México. La caótica democracia de las asambleas multitudinarias dio paso a la toma de decisiones por parte de las ONG y los gobiernos burócratas. La posibilidad prometida por el hecho de que los migrantes negociaran por sí mismos con la policía mexicana, se enfrentó a la amenaza total de las fuerzas armadas de Estados Unidos. Cuando el objetivo dejó de ser atravesar, se desafió a la combinación 
Amelia Frank-Vitale

Margarita Núñez Chaim
"Lady frijoles": las caravanas centroamericanas y el poder...

radical entre movimiento y protesta que había apuntalado a la caravana desde el principio. Entrar requería que las personas migrantes pasaran de la acción colectiva a los actos individuales.

Finalmente, en la frontera, había tres opciones disponibles: (1) tomar un número y solicitar asilo en Estados Unidos; (2) permanecer en Tijuana indefinidamente, y quizás aceptar la oferta de visas humanitarias del gobierno mexicano; y (3) contratar a un coyote para que los llevara clandestinamente a través de la frontera. Cada una de estas opciones refleja la forma en que el Estado obliga a retroceder el desafío que presentó la caravana a través de su visibilidad radical, hacia los canales de legibilidad, legalidad e invisibilidad, desarticulando el poder de la acción colectiva y atomizando la caravana en sus partes individuales. El asilo en el sistema estadounidense es explícitamente una petición individual (o de una familia nuclear) ${ }^{12}$. Si bien gran parte de la infraestructura de solidaridad construida en Tijuana para ayudar al éxodo centroamericano giraba en torno a preparar a las personas para ingresar al sistema de asilo, cada una debe entregarse de forma individual, y luego cada caso será evaluado por sus circunstancias particulares. A pesar de que ha habido movimientos sociales que han logrado la protección colectiva en Estados Unidos - como el Estatus de Protección Temporal (TPS) y la Acción Diferida para los Llegados en la Infancia (DACA) que surgieron como resultado de tales movimientos (Perla and Coutin, 2009; Coutin, 2016; Flores, 2016; Heredia, 2016) - el proceso para obtener el estatus aún requiere una serie de obligaciones individuales con el sistema legal.

Con el tiempo, aquellos que optaron por la visa humanitaria en México abandonaron el campamento improvisado y comenzaron a establecer una vida por sí mismos en Tijuana. Al igual que con el asilo en Estados Unidos, estos permisos mexicanos se basan en solicitudes individuales, muchas veces acompañadas por la solicitud de la condición de refugiado en México. Después las personas recurrieron a sus redes familiares y sociales particulares para encontrar trabajo y vivienda en Tijuana. Conforme las y los caravaneros se fueron incorporando al mercado laboral local, dejaron de ser parte de la colectividad de la caravana y pasaron de ser hípervisibles a invisibles. Jairo

\footnotetext{
${ }^{12}$ Existe una curiosa tensión subyacente en la ley de asilo, ya que si bien el reclamo lo hace el individuo (o la familia nuclear), para tener un caso de asilo exitoso, la persecución que el individuo sufrió en su país de origen tuvo que ser debido a la pertenencia inmutable de esa persona a una comunidad o grupo social que es perseguido (McCuiston, 2015).
} 
eligió esta alternativa, por miedo a ser deportado de regreso a Honduras en caso de que buscara asilo en Estados Unidos. Después de unas semanas trabajando en Tijuana, había adoptado el vocabulario y las entonaciones de un "norteño", suavizando sus "eses" aspiradas en la dicción más dura del español mexicano y cambiando "pucha” por "caray." No quería que lo señalaran por ser hondureño en su lugar de trabajo, me dijo. Era más fácil si no era tan obvio. El estatus legal en Tijuana significó un retorno a la invisibilidad para los caravaneros como Jairo.

Como hemos argumentado, el poder de la caravana como acción colectiva radica en su hípervisibilidad. El poder de la caravana no se basa en el número de personas que participan, sino en el movimiento abierto y con la cabeza en alto de las y los caravaneros a través de México y su reivindicación, en cada paso del camino, de que tienen derecho a hacerlo. Cientos de miles de personas de Centroamérica se mueven clandestinamente por México cada año, con el objetivo de llegar a los Estados Unidos. Las 10,000 personas que participaron en el éxodo son apenas una pequeña fracción de la población que participa en la migración de tránsito indocumentada. Sin embargo, las otras personas lo hacen en las sombras, colándose en los márgenes de México, haciendo todo lo posible para pasar desapercibidos.

Esta invisibilidad obligada (Angulo-Pasel, 2019) favorece a todos aquellos que se aprovechan de la vulnerabilidad y se benefician de la migración indocumentada: cárteles de drogas, redes de tráfico, agentes de inmigración y policías $^{13}$, así como la microeconomía que existe a lo largo de la ruta de migración. Enfrentarse a la frontera en Tijuana también hace retroceder la acción colectiva hípervisible hacia los riesgos y peligros del cruce fronterizo clandestino. Debido a la atención que trajo la caravana al sector, los coyotes en Tijuana empezaron a cobrar $\$ 10,000$ dólares por persona para llevarles a Estados Unidos. Muchas y muchos caravaneros, aquellos que no querían probar suerte con el asilo y no se resignaron a quedarse en Tijuana, esperaron con la caravana hasta que sus familias reunieron el dinero para un coyote y se trasladaron lateralmente a otras fronteras, regresando a las sombras. Omar,

${ }^{13}$ Incluímos a agentes de inmigración y policías aquí por dos razones: por un lado, la aplicación de la ley de inmigración es una industria multimillonaria y el foco de un extenso apoyo financiero y logístico de Estados Unidos. Al mismo tiempo, la corrupción de los funcionarios de inmigración y la policía está profundamente arraigada, tanto en México como en Estados Unidos, y algunos incluso llaman al instituto de inmigración de México el mayor "cártel" involucrado en el tráfico de personas. 
Amelia Frank-Vitale

Margarita Núñez Chaim
"Lady frijoles": las caravanas centroamericanas y el poder...

originario de Yoro, Honduras, ya había sido deportado una vez el año anterior, por lo que pensó que no tendría mucha suerte con el asilo. Además, todavía tenía otro viaje con el coyote que su familia había contratado el año anterior ${ }^{14}$. Cuando le dijeron que se moviera, se subió a un autobús desde Tijuana y viajó a Monterrey, donde esperaría en una casa de seguridad durante un mes, antes de que el coyote le dijera que era hora de irse.

A través de los mecanismos disponibles para las personas del éxodo una vez que se enfrentaron a la frontera norte, la acción colectiva se retrajo a elecciones individuales. Esto fue deliberado, ya que tanto el gobierno mexicano como el de Estados Unidos preferirían lidiar con migrantes individuales y solicitantes de asilo (la mayoría de los cuales serán rechazados y deportados), que con un grupo organizado de personas involucradas en una desobediencia civil (Celikates, 2019) y exigiendo que se les permita entrar. Solo podemos hacer hipótesis sobre lo que podría haber sucedido si todas y todos los caravaneros se hubieran resistido a los caminos individuales disponibles $y$ hubieran desarrollado un nuevo tipo de acción colectiva, aún desconocida e inimaginable. Sin embargo, muchas y muchos centroamericanos, huyendo de situaciones desesperadas y desgastados por semanas y meses de dormir en el concreto y vivir en carpas, estaban ansiosos por lograr la probabilidad de la estabilidad que se encuentra en las vías conocidas, por sobre la posibilidad de algo más, algo nuevo e inimaginable, más allá de las fronteras de lo conocido.

La caravana de 2018, aunque fue la más grande y mejor reportada de las caravanas de migrantes, no surgió repentinamente, sin precedentes. Este movimiento de migrantes ha estado creciendo durante más de una década en México (Martínez Hernández-Mejía, 2018; Balaguera y Gonzales, 2018), basándose en una larga tradición de caravanas de protesta (Domínguez Ruvalcaba, 2017; Torres-Ruiz, 2018). Con esto en mente, sugerimos que esta confrontación con la frontera que disipó la caravana no es el fin de la migración como movimiento, sino más bien, un momento que requiere de la emergencia de nuevas formas de organización y nuevas tácticas, para desafiar el régimen regional de migración que busca sujetar a las personas en un lugar. Las personas, ya sean centroamericanas o de otras regiones, siempre se negarán a quedarse quietas cuando las condiciones de vida sean inadecuadas. Es probable que las

\footnotetext{
${ }^{14}$ Por lo general, los coyotes ofrecen tres viajes por el precio de uno. Si una persona es deportada la primera y la segunda vez, aún puede volver, sin pagar una tarifa adicional, más allá de cubrir sus propios costos de alojamiento y comida.
} 
caravanas como las de 2018 no vuelvan a ocurrir de la misma forma: tanto la frustración del encuentro en la frontera norte como la represión severa de las caravanas posteriores en el sur de México se han encargado de esto, pero a partir de los éxitos, los fracasos y las múltiples reacciones a la caravana 2018 surgirán nuevas formas de acción colectiva y protesta.

\section{Conclusiones}

A casi un ańo de que la caravana de 2018 arrancara con unas 300 personas de la terminal de autobuses de San Pedro Sula, Honduras, podemos reflexionar sobre los logros y desafíos del largo plazo del movimiento de migrantes. La hondureña conocida como "lady frijoles" logró entrar en Estados Unidos y volvió a ser noticia cuando la arrestaron y la acusaron de haber participado en algún acto delictivo. En el momento de escribir el presente artículo, ella está esperando su juicio y, sean cuales sean los resultados de la investigación, al final del proceso lo más probable es que la deporten a Honduras.

De las y los miles de caravaneros, varios siguen retenidos en centros de detención en Estados Unidos, esperando pelear sus casos de asilo. Muchas y muchos fueron encarcelados por un tiempo corto y ya fueron deportados a Honduras otra vez, entre ellos, Omar. De ellos, conocemos a varios quienes volvieron a intentar cruzar México, en otras caravanas más pequeñas y menos mediáticas o por otros medios. Hay otras y otros caravaneros desaparecidos, secuestrados, y asesinados, tanto en México como después de haber sido deportados a sus países de origen. Así que el reto que plantea la caravana está en su forma, una migración con la cabeza en alto de las y los migrantes en su paso, pero falta mucho - mucha acción, mucha organización, mucha consciencia, mucho más radical e insurreccional que las caravanas - para que las estructuras estatales y globales se vean obligadas a aceptar y garantizar el derecho a migrar de manera libre y digna. 
Amelia Frank-Vitale

Margarita Núñez Chaim
"Lady frijoles": las caravanas centroamericanas y el poder...

\section{Bibliografía}

Angulo-Pasel, Carla (2019) "The categorized and invisible: the effects of the 'Border' on women migrant transit flows in Mexico." en Social Sciences. No. 8 (5): 144. https://doi.org/10.3390/socsci8050144.

Balaguera, Martha, y Alfonso Gonzales, (2018) "On the migrant trail, a refugee movement emerges." en NACLA Report on the Americas. January. Disponible en: https://nacla.org/blog/2018/01/29/migranttrail-refugee-movement-emerges.

Bhimji, Fazila, (2016) "Visibilities and the politics of space: refugee activism in Berlin." en Journal of immigrant and refugee studies. No.14 (4): 432-50. Disponible en: https://doi.org/10.1080/15562948.2016.1 145777.

Butler, Judith, (2016) "Rethinking vulnerability and resistance." en Butler, Judith; Gambetti, Zeynep and Leticia Sabsay (eds.) Vulnerability in resistance. 12-27. Durham: Duke University Press.

Butler, Judith; Gambetti, Zeynep and Leticia Sabsay, (2016) Vulnerability in resistance. Durham: Duke University Press.

Celikates, Robin, (2019) "Constituent power beyond exceptionalism: irregular migration, disobedience, and (re-)constitution." en Journal of international political theory. No. 15 (1): 67-81. Disponible en: https://doi.org/10.1177/1755088218808311.

Córdoba González de Chávez, Daniel, (2018) “(In)Visibilidad y resistencia. ciudadanías clandestinas y activismo migrante transnacional (In)Visibility and resistance. clandestine citizenships and transnational migrant activism." en Relaciones internacionales. No. 39 (August). Disponible en: https://doi.org/10.15366/ relacionesinternacionales2018.39.011.

Coutin, Susan Bibler, (2016) Exiled home: Salvadoran transnational youth in the aftermath of violence. Durham: Duke University Press Books. 
Amelia Frank-Vitale

Margarita Núñez Chaim
"Lady frijoles": las caravanas centroamericanas y el poder...

De Vries, Leonie Ansems, (2016) "Politics of (in)visibility: governanceresistance and the constitution of refugee subjectivities in Malaysia." en Review of international studies. No. 42 (5): 876. Disponible en: https://doi.org/10.1017/S0260210516000103.

Domínguez Ruvalcaba, Héctor, (2017) "Poesía de calle: activismo poético contra la violencia en México." en Tintas. Quaderni di letterature iberiche e iberoamericane. No. 7: 79-91.

Flores, William, (2016) "Undocumented and unafraid: the emergence of an undocumented movement and its impact on immigration policy, the DREAM Act, DACA, DAPA, and family unification." en Journal of family strengths. No.16 (1). Disponible en: https://digitalcommons. library.tmc.edu/jfs/vol16/iss1/3.

Frank-Vitale, Amelia, (2019) "Rolling the windows up: on (not) researching violence and strategic distance." en Geopolitics. September, 1-20. Disponible en: https://doi.org/10.1080/14650045.2019.1662396.

Frank-Vitale, Amelia, (2011) "Master's thesis: Guerreros del camino: Central American migration through Mexico and undocumented migration as civil disobedience”. Washington, DC: American University.

Hammer, Gili, (2016) "If they're going to stare, at least I'll give them a good reason to': blind women's visibility, invisibility, and encounters with the gaze." en Signs: journal of women in culture and society. No. 41 (2): 409-32. Disponible en: https://doi.org/10.1086/682924.

Heredia, Luisa Laura, (2016) "More than DREAMs." en NACLA Report on the americas. No. 48 (1): 59-67. Disponible en: https://doi.org/10.1 080/10714839.2016.1170304.

Martínez Hernández-Mejía, Iliana, (2018) "Reflexiones sobre la caravana migrante." en Análisisplural. Vol. primer semestre. Tlaquepaque, Jalisco: ITESO. Disponible en: https://rei.iteso.mx/handle/11117/5616.

McCuiston, Hannah, (2015) “'Membership in a particular social group': why United States courts should adopt the disjunctive approach of the 
Amelia Frank-Vitale

Margarita Núñez Chaim
"Lady frijoles": las caravanas centroamericanas y el poder...

United Nations High Commissioner for Refugees.” en St. John's Law Review. 88 (No. 2, Article 8): 31.

McFalls, Laurence, (2010) "Benevolent dictatorship: the formal logic of humanitarian government." en Fassin, Didier y Mariella Pandolfi (eds.) Contemporary states of emergency: the politics of military and humanitarian interventions. [1 edition]. New York: Cambridge, Mass: Zone Books.

Mowatt, Rasul A.; French, Bryana H. and Dominique A. Malebranche, (2013) "Black/female/body hypervisibility and invisibility: a black feminist augmentation of feminist leisure research." en Journal of leisure research. No. 45 (5): 644-60. Disponible en: https://doi. org/10.18666/jlr-2013-v45-i5-4367.

Perla, Hector y Susan Bibler Coutin, (2009) "Legacies and origins of the 1980s US--Central american sanctuary movement.” en Refuge. No. 26 (1): 7.

Ruiz-Giménez Arrieta, Itziar, (2017) "Una mirada crítica al «humanitarismo» desde los estudios pospositivistas / A critical post-positivist studies perspective on 'humanitarianism."” en Revista CIDOB d'Afers Internacionals. No. 117: 173-96.

Shams, Tahseen, (2018) "Visibility as resistance by Muslim Americans in a surveillance and security atmosphere.” en Sociological Forum. No. 33 (1): 73-94. Disponible en: https://doi.org/10.1111/socf.12401.

Ticktin, Miriam, (2006) "Where ethics and politics meet: the violence of humanitarianism in France." en American Ethnologist. No. 33 (1): 33-49.

Torres-Ruiz, René, (2018) "Movimientos sociales y democracia en el México contemporáneo." en Iberofórum. Revista de Ciencias Sociales de La Universidad Iberoamericana. No. Año XIII, No. 26 (July): 190-215. 